\title{
La mentira histórica de un pirata caribeño: el descubrimiento del trasfondo histórico de los Infortunios de Alonso Ramírez (1690) ${ }^{1}$
}

\author{
Fabio López Lázaro \\ Santa Clara University
}

El presente trabajo se centra en ofrecer una prueba documental contundente, contextualizada históricamente, de que el texto producido por la colaboración entre Carlos de Sigüenza y Góngora y Alonso Ramírez en 1690 no fue ficción sino relato basado en las experiencias verdaderas de un marinero puertorriqueño. Se trata de la correspondencia entre el conde de Galve, virrey de la Nueva España, y su hermano, el duque del Infantado, ambos opuestos al partido dirigido por el cardenal-arzobispo Portocarrero que triunfó al acceder los Borbones al trono en 1700. Por consiguiente se propone que hay que ver la producción del texto de los Infortunios como un eslabón en la estrategia política e imperial.

PAlABras Clave: Infortunios de Alonso Ramírez, imperio, Carlos II, piratas, nobleza, literatura colonial, Gran Alianza, historia marítima, Guerra de la Liga de Augsburgo.

The present work focuses on offering incontrovertible documentary proof, contextualized historically, that the text produced by the collaboration of Carlos de Sigüenza $y$ Góngora and Alonso Ramírez in 1690, was not fictional but rather an account based on the real experiences of a Puerto Rican mariner. The evidence comes from the correspondence between the Count of Galve, Viceroy of New Spain, and his brother, the Duke of Infantado, both opposed to the court party led by the Cardenal-Archbishop Portocarrero, which would only come to power with the Bourbon accession of 1700. Consequently, we must re-evaluate the creation of the Infortunios as a step in the political and imperial strategies.

KEYwords: Pirates, colonial literature, imperialism, Carlos de Sigüenza y Góngora, aristocrats, Grand Alliance, Alonso Ramírez, Charles II.

Como los medios son cortos para tan gran máquina, temo que no han de alcanzar a tanto como se abarca...2

Felipe IV, 12 de febrero de 1657

1 Quisiera reconocer el apoyo recibido de la Universidad de Santa Clara, especialmente varias becas de investigación "Thomas Terry" concedidas entre 2004 y 2006 que me permitieron visitar archivos en España, Francia, Holanda, Inglaterra y México para escribir el libro al cual se refiere este trabajo, que aparecerá próximamente publicado por la imprenta University of Texas Press bajo el título de The Spanish Empire Strikes Back: Seventeenth-century Piracy and the Misfortunes of Alonso Ramírez.

2 La versión filipina del proverbio "El que mucho abarca, poco aprieta", su descripción de la penuria imperial típica de este período en Silvela, Francisco: Cartas de la venerable madre, Sor María de Agreda y del Señor Rey Don Felipe IV, precedidas de un bosquejo histórico, Sucesores de 
La historicidad de textos se establece penosamente. Sin recurrir a los archivos para comprobar su veracidad, sin embargo, es imposible distinguir la verdad o mentira histórica de las imaginaciones ficticias, es decir, los hechos tal y como los relata el testigo ocular de como los imagina un escritor. Cabe notar, en este contexto, que las fuentes archivísticas comparten con la literatura la ambigüedad inherente a toda narración de "hechos", la problemática de su veracidad. En torno al caso del libro que se piensa compuso don Carlos de Sigüenza y Góngora en 1690 bajo el título de los Infortunios de Alonso Ramírez [Infortunios que padeció Alonso Ramírez...], los historiadores nos hemos quedado a la zaga de los estudiosos de la literatura. Desde que empezó a interesar seriamente este pequeño libro como tema académico hace apenas cien años, son los investigadores literarios los que han analizado con mayor ventaja su valor como literatura mundial y su conexión con otras novelas tales como el Periquillo Sarniento, pero sin descubrir los detalles complejos de su composición. ${ }^{3} \mathrm{La}$ opinión más generalizada sigue siendo que esta obra es importante por su contribución al desarrollo de la novela colonial latinoamericana. No obstante, existen pruebas en los archivos coloniales de Europa que demuestran que esta pieza no nació de la imaginación calenturienta del cosmógrafo en la ciudad de México, sino como texto de complicada historia, cuyo fondo radica en las experiencias de un verdadero marinero hispano que arribó a las costas de la Nueva España en el otoño de 1689.4 Aunque se debate el tema de la historicidad de Los infortunios desde que apareció en 1902 la edición de Pedro Vindel (parte de la serie "Colección de libros raros y

Rivadeneyra, Madrid, 1885-1886, vol. 2, pág. 465. El pesimismo en cuanto a la financiación imperial lo compartía Felipe con otros monarcas, como Luis XIV, por ejemplo, cuyos problemas describe en una carta a su ministro Colbert fechada en junio de 1683 en términos similares: "La grande despence me fait beaucoup de peine; mais il y en a de nécessaires", citada en Potter, Mark: Corps and Clienteles: Public Finance and Political Change in France, 1688-1715, Ashgate, Aldershot, Inglaterra y Burlington, EE.UU., 2003, pág. ii.

3 En el apéndice a su edición del texto, "La proyección de Infortunios de Alonso Ramírez en la primera novela mexicana del siglo XIX”, Infortunios de Alonso Ramírez, Historia 16, Madrid, 1988, págs.141-145, Lucrecio Pérez Blanco atribuye al autor del Periquillo un "trasvase" del "pensamiento sigüencino...en contenido y estructura literaria". De tal manera influyó el cosmógrafo mexicano en esta notabilísima obra que "puede sostenerse así también que Don Carlos de Sigüenza y Góngora inaugura lo que se mantiene en la tradición literaria de su patria: La preocupación por la idiosincrasia y los comportamientos del hombre y de la sociedad mexicana".

4 Se equivoca Alba Vallés Formosa al decir que Sigüenza y Góngora no obtuvo el título de cosmógrafo real hasta 1693, (Infortunios de Alonso Ramírez, Cordillera, San Juan de Puerto Rico, 1967, pág. 25), según probó hace tiempo Irving Leonard en sus muchos trabajos sobre el erudito, especialmente Don Carlos de Sigüenza y Góngora: A Mexican Savant of the Seventeenth Century, University of California Press, Berkeley, California, 1929, pág. 75n.1. 
curiosos que tratan de América"), no se ha podido reivindicar el carácter fundamentalmente histórico de este texto fechado en el siglo XVII hasta los descubrimientos presentados por primera vez al lector en este trabajo. ${ }^{5}$

\section{La perspectiva literario-historiográfica}

Apenas existió interés por la obra de Sigüenza y Góngora en los dos siglos posteriores a su aparición; Infortunios de Alonso Ramírez se volvió a descubrir como texto importante sólo a comienzos del siglo XX. Los escritores latinoamericanos en general, y nacionalistas en particular, buscando la herencia criolla, se entusiasmaron por la narración interesantísima de las peripecias de este hijo aventurero de las Américas en la Nueva España, Asia y el Caribe con la misma emoción que causan todavía. En parte estos lectores, simples o académicos, disfrutaron meramente al hallar en los Infortunios prueba fehaciente de que las Américas se resistieron en el XVII a las disposiciones legales de 1532 y 1543 prohibiendo "que se imprimieran o se trajesen de Europa obras de ficción, ya fuera en prosa o en verso," como señaló Alba Vallés Formosa en $1967 .{ }^{6}$ No es de extrañar, pues, que el relato de Alonso Ramírez suscitara tanto interés, teniendo en cuenta que sus episodios novelísticos - el secuestro por piratas ingleses, la esclavitud entre bucaneros en el océano Índico y, finalmente, el naufragio en el litoral caribeño del Yucatán- concordaron con los deseos literarios de poblar aquel hemisferio con héroes americanos, no embargante su carácter ficticio. Así, se volvieron a publicar varias versiones del texto original, la mayor parte sin aparato crítico, en México en 1940, 1945, 1960, 1962, 1964, 1982 y 2003, en Argentina en 1944, en Puerto Rico —-tardíamente, dada la supuesta patria de Alonso- en 1967 y 1990, en Venezuela en 1984 y en Madrid en 1988. ${ }^{7}$ Últimamente se ha perdido interés por el tema de

5 El presente trabajo se basa en el estudio profundizado de la historicidad de este texto y de su importancia dentro del imperialismo aristocrático hispano bajo Carlos II que aparecerá pronto bajo el título de The Spanish Empire Strikes Back: Seventeenth-Century Piracy and the Misfortunes of Alonso Ramirez, publicado por University of Texas Press.

6 Alba Vallés Formosa, siguiendo las investigaciones de Henríquez Ureña, Pedro: Infortunios de Alonso Ramírez, Cordillera, San Juan de Puerto Rico, 1967, pág. 9.

7 El redescubrimiento académico se lo debemos a Vindel, Pedro: Infortunios de Alonso Ramírez, Relación de la América Septentrional por Luis Hennepin, Viuda de G. Pedraza, Madrid, 1902. Véase también la nota bibliográfica sobre el interés del erudito Beristáin y Souza en el siglo XIX en el estudio crítico de Rodilla, María José: Infortunios de Alonso Ramírez, Alfaguara, México, 2003, que contiene una relación breve de las varias ediciones en las páginas 113-115. 
Los infortunios, como demuestra la falta de estudios sobre el texto en el homenaje coordinado por Alicia Mayer en México, dedicado al tricentenario de la muerte de Sigüenza y Góngora el 22 de agosto de $1700 .{ }^{8}$ Entre éstas destacan por el énfasis histórico de su mira las dos ediciones de 1984 (Londres y Caracas) y la de 1990 (Puerto Rico).

Casi todos los editores más recientes de esta obra repiten los detalles que relatan el origen del texto tal y como nos lo cuenta el narrador en la edición de 1690, en su prólogo dedicado al virrey de Nueva España, el conde de Galve, así como los que expone el protagonista mismo, Alonso Ramírez, al final de ella. No obstante, ha sido imposible hasta ahora comprobar los detalles. En la dedicatoria es Sigüenza y Góngora, científico con varios cometidos en la corte virreinal de Galve, quien ofrece el relato ramirense al conde como muestra del magnánimo amparo virreinal para necesitados semejantes al protagonista, Alonso Ramírez, a la vez que publica el libro en testimonio de la buena política que este gobernante estaba realizando desde 1688. "Cerró Alonso Ramírez en México el círculo de sus trabajos", nos cuenta Sigüenza y Góngora,

con que apresado de ingleses piratas en Filipinas, varando en las costas de Yucatán en esta América dió vuelta al mundo; y condoliéndose Vuestra Excelencia de él cuando los refería, quién dudará el que sea objeto de su munificencia en lo de adelante, sino quien no supiere el que templando Vuestra Excelencia con su conmiseración su grandeza tan reciprocamente las concilia, que las iguala, sin que pueda discernir la perspicacia más lince cual sea antes en Vuestra Excelencia, lo grande heredado de sus progenitores excelentísimos o la piedad connatural de no negarse compasivo a los gemidos tristes de cuantos lastimados la solicitan en sus afanes. Alentado pues con lo que de ésta veo cada día prácticamente, y con el seguro de que jamás se cierran las puertas del palacio de Vuestra Excelencia a los desvalidos en nombre de quien me dió el asunto para escribirla, consagro a las aras de la benignidad de Vuestra Excelencia esta peregrinación lastimosa, confiado desde luego, por lo que me toca, que en la crisis altísima que sabe hacer con espanto mío de la hidrografía y geografía del mundo, tendrá patrocinio y merecimientos. ${ }^{9}$

No faltan lectores modernos cuidadosos, como J.S. Cummins y Alan Soons en 1984, que no se hayan fijado en cómo los contemporáneos perspicaces se habrían dado cuenta del candor falso de Sigüenza y Góngora al

8 Carlos de Sigüenza y Góngora: Homenaje, 1700-2000, Alicia Mayer (coord.), Universidad Nacional Autónoma de México, México, 2000, 2 volúmenes.

9 Uno de los únicos ejemplares del original de 1690 se guarda en la Hispanic Society of America, cuyo texto incluyó Estelle Irizarry en edición facsímil, pero desafortunadamente sin paginar, en Infortunios de Alonso Ramírez, Comisión Puertorriqueña para la Celebración del Quinto Centenario del Descubrimiento de América y Puerto Rico, Río Piedras [San Juan], 1990. 
final de la dedicatoria, puesto que toda la corte en el México de 1690 reconocería la auto-alabanza que consta en ella. "La crisis altísima" que realiza el narrador "con espanto mío de la hidrografía y geografía del mundo" era frase autorreferente que ponía en evidencia precisamente los retoques científicos que debió de dar el cosmógrafo a los conocimientos rudimentarios que tuviera el carpintero puertorriqueño.

Aún así, o posiblemente a causa de la autorreferencia, muchos han leído los Infortunios con escepticismo sin aceptar que existieran ni el marinero puertorriqueño ni sus aventuras, aunque sobren detalles acerca de la composición textual al final del relato, detalles que Sigüenza y Góngora pone en voz de Alonso Ramírez. El "desvalido" que amparó el virrey, en este caso Alonso Ramírez, nos dice más detalladamente él mismo en el último párrafo del libro cómo se formuló el texto de los Infortunios. El viernes 5 de mayo de 1690 (no el 5 de abril, error tipográfico manifiesto), ${ }^{10}$ un día después de arribar a la ciudad de México desde Veracruz, se le concedió a Alonso audiencia con el virrey quien, "compareciéndose primero de mis trabajos y congratulándome de mi libertad con parabienes y plácemes, escuchó atento cuanto en la vuelta entera que he dado al mundo queda escrito". Pero en esa ocasión, continúa Alonso, "sólo le insinué a su Excelencia en compendio breve" las penas que había padecido, por lo cual, "mandome (o por el afecto con que lo mira o quizá porque estando enfermo divirtiese sus males con la noticia que yo le daría de los muchos míos) fuese a visitar a Don Carlos de Sigüenza y Góngora". Éste, "compadecido de mis trabajos, no sólo formó esta Relación...sino que me consiguió" socorros en efectivo "con la intercesión y súplicas que en mi presencia hizo al Excelentísimo Señor Virrey". Por lo visto, si no se trata de una invención de Sigüenza y Góngora a la cual el conde de Galve dio crédito, ambos juzgaron que lo que les contaba Alonso era verosímil — cabe la posibilidad, que prontamente descartaremos por más que se haya llevado la palma entre los críticos literarios, de que la escena de mayo de 1690 entre náufrago, autor y virrey fueran pura ficción-.

La aprobación de don Francisco de Ayerra Santa María, fechada en 26 de junio de 1690, asimismo, nos demuestra que la opinión de otros contem-

10 Lo corrigen Cummins y Soons en su versión del texto, Los infortunios de Alonso Ramírez, Tamesis, Londres, 1984, pág. 70, y William G. Bryant en la suya, Seis Obras: Infortunios de Alonso Ramírez, Trofeo de la justicia española, Alboroto y motín, Mercurio volante, Teatro de virtudes políticas, Libra astronómica y filosófica, Biblioteca Ayacucho, Caracas, 1984, pero no Pérez Blanco, Infortunios, pág. 129. 
poráneos importantes fue que "la relación de los infortunios de Alonso Ramírez" era histórica. Como "compatriota" de Ramírez — nacido igualmente en Puerto Rico - el famoso poeta Ayerra Santa María informa en su censura que el cosmógrafo mexicano sólo "describió" las aventuras de Ramírez, aunque las pulió "con su lima" de erudito. La labor de Sigüenza y Góngora sirvió para plasmar lo oral en el texto, igual que las tribulaciones de Job sólo se hicieron memoria didáctica para los siglos por vía de su inclusión en la Biblia: "Para eternizar Job lo que refería deseaba quien lo escribiera...este quis mihi tribuat de Job halló (y halló cuanto podía desear) el sujeto [Ramírez] en el autor de esta relación [Sigüenza y Góngora] que para noticia y utilidad común por no tener cosa digna de censura será muy conveniente que la eternice la prensa". ${ }^{11}$

Es difícil averiguar, sin servir de impedimento la conformidad de estos tres personajes, hasta qué punto aceptaron el relato de Alonso como verídico la mayoría de sus contemporáneos. Les resultaría casi imposible, de todos modos, comprobar los detalles al no tener a su disposición todos los documentos necesarios para revisarlos de manera sistemática. Que sepamos, por lo menos un individuo desconfió de Ramírez: don Ceferino de Castro, uno de los dos alcaldes de la villa de Valladolid, a medio camino entre la capital de Yucatán (Mérida) y la zona que sólo desde 1734 se conoce comúnmente como la costa de Cancún. ${ }^{12}$ Tal personaje aparece en los archivos y, aunque poco sabemos de él, lo que sí confirman sus títulos es importantísimo a la larga, como veremos, pues heredó el puesto de fiel ejecutor de la villa en abril de 1689, poco antes de llegar Ramírez a las costas bajo su jurisdicción. ${ }^{13}$ El fiel ejecutor de entonces, según el Diccionario de la Real Academia (1732), se encargaba "del reconocimiento de los pesos y medidas de que usan los que venden" y además debía "examinar si los

11 Citando siempre por la edición facsímil de Irizarry, Estelle: Infortunios de Alonso..., 1990.

12 Andrews, Anthony, P.: "Some Historic Notes and Observations on Isla Cancún, Quintana Roo," 3 [Foundation for the Advancement of Mesoamerican Studies, http://research.famsi.org/aztlan/ uploads/papers/Andrews-Cancun-Aztlan-06-2.pdf, 5 de junio de 2007].

13 Don Ceferino de Castro y Velasco se confirmó como regidor y fiel ejecutor de la villa el 21 de abril de 1689; tomó el título "por juro de heredad" de su padre y abuelo, Archivo General de Indias (AGI), México, 198, 50. Véase también García Bernal, Manuela Cristina: Población y encomienda en Yucatán bajo los Austrias, Escuela de Estudios Hispano-Americanos, Sevilla, 1978, pág. 527, seguida por Bryant: Seis obras. Infortunios de Alonso Ramírez, Trofeo de la justicia española, Alboroto y motín, Mercurio volante, Teatro de las virtudes políticas, Libra astronómica y filosófica, Biblioteca Ayacucho, Caracas, 1984, 46n.98, quien recoge las pruebas para su encomienda de 120 indios en 1688 en el pueblo de Yalcoba, y Lorente Medina, Antonio: La prosa de Sigüenza y Góngora y la formación de la conciencia criolla mexicana, Fondo de Cultura Económica, México, 1996, pág.177. 
géneros que dan son cabales". Con la notable excepción de don Ceferino, cuyas sospechas, según el texto, las suscitó un kris o daga de tipo asiático que Alonso confesó haber regalado a un aristócrata yucateco, el virrey y el poeta que dio su aprobación a la publicación del libro se creyeron ambos que Alonso no sólo no se lo inventó el cosmógrafo sino que los dos contaron la verdad. No obstante tales aseveraciones textuales, la mayoría de los lectores lo han considerado todo casi como un cuento de hadas colonial.

Resulta interesante la caracterización de Sigüenza y Góngora que hizo su sobrino cuando murió su tío en 1700, en vista de la incredulidad de los lectores de hoy, lo que se opone a la opinión predominante de los contemporáneos de los hechos narrados en los Infortunios. En una carta al vicario episcopal, don Antonio de Aunzibay y Anaya, describió al cosmógrafo de la siguiente manera: ${ }^{14}$

\begin{abstract}
No alcanzo modo para explicar las prendas con que Dios Nuestro Señor le había dotado, afable, comunicativo, compuesto en sus palabras, modesto y ejemplar en la calle y dentro de su casa rígido, caritativo, principalmente con los enfermos y amigo de hacer bien a todos, sin interés ninguno; amigo de la verdad, abominando la mentira y malicias, y al fin hombre compuesto y medido en todas sus cosas y erudito en todas las ciencias, como a todos consta. ${ }^{15}$
\end{abstract}

Aún así, los enredos verdaderamente novelescos de los Infortunios, más propios de la trama del capitán Sangre de Rafael Sabatini o de la película Piratas del Caribe que de un relato fidedigno e histórico, les han impedido a sus lectores creer que no se los inventó don Carlos. Las "múltiples lecturas" a las cuales nos invita Pérez Blanco, por ejemplo, incluyen "la del historiador" pero, siguiendo la pauta establecida por otros, no le concede al texto "las dimensiones puras de la realidad," aunque se resiste este crítico, también típicamente, a desvirtuar "la honestidad del escritorhistoriador [Sigüenza y Góngora]" ${ }^{16}$ La indecisión crítica sobre la historicidad del texto abarca así múltiples cuestiones que no sólo se encaminan a problematizar la credulidad del lector moderno sino también las del virrey y el cosmógrafo.

14 Para un estudio de esta carta, véase Escamilla González, I.: "La epístola dedicatoria de Gabriel López de Sigüenza para el Oriental planeta evangélico: Nota introductoria”, parte II de la colección de ensayos coordinados por Alicia Mayer, Carlos de Sigüenza y Góngora: Homenaje, 1700 2000 , volumen II.

15 Citada en Rodilla: Infortunios..., págs. 127-128.

16 Pérez Blanco: "Introducción", Infortunios de Alonso Ramírez, págs. 7-8. 
En la estimación de Emilio Carilla, aparecida en 1949, el cuento de Alonso Ramírez es "El Robinson americano", lleno de coincidencias literarias con la historia de aquel otro náufrago más famoso. ${ }^{17}$ Cuarenta años más adelante José Joaquín Blanco notaba la incoherencia narrativa de los Infortunios, la yuxtaposición inesperada de la voz de Alonso con la del científico pedante, lo cual era compendio de "una especie de pícaro conversando con la elegancia y riqueza verbal, sintáctica, moral y geográfica de un catedrático...; a veces el pobre náufrago habla más como cosmógrafo en cátedra que como el lamentable y sencillo hombre de Dios sobre el que se abatieron las calamidades, entre las que no fue la menor la corrupción de la propia burocracia novohispana". Asimismo, subraya las semejanzas del texto híbrido creado por el marinero y Sigüenza y Góngora con otras obras pseudo-históricas y marítimo-literarias, como las "de Swift, de Defoe, de Stevenson y de Conrad". ${ }^{18}$ En 1967 Vallés Formosa trató el tema de la historicidad de los Infortunios con destreza en su edición crítica, refiriéndose a los estudios de Luis Alberto Sánchez de 1953 y de Anderson Imbert de 1954, en los que ambos optaban por la esencia novelística del texto, aunque Imbert pensó que "el autor intercala conceptos y creencias de su propia creación dentro de un relato que de alguna manera sin establecer constituía un texto histórico". Es posible incluso, añade Vallés Formosa, que el autor del Robinson Crusoe, Defoe, "hubiera tenido noticia del texto de Sigüenza y Góngora". No obstante, difieren los Infortunios de la famosa novela inglesa en cuanto al peso de la imaginación del autor en la redacción del texto: en vez de "la vida novelada de un marinero" de verdad, "el Alonso Ramírez tiene que ceñirse a un relato más real y conocido, aunque expuesto con técnica novelesca". La falta de pruebas extra-textuales para la existencia de Alonso Ramírez y sus aventuras ha constituido el obstáculo que le impidió a Vallés Formosa romper con esta interpretación novelística: "Nuestro protagonista es, pues, el típico de la novela hispanoamericana", concluye, y no la voz auténtica de un marinero puertorriqueño. Para María José Rodilla, Infortunios es eminentemente un texto con valor histórico a tenor del testimonio social de La lozana andaluza de Francisco Delicado y de "los juegos cervantinos de autor, narrador y personajes lectores de la novela, dentro de la novela misma, en El Quijote". Sin embar-

17 "El Robinson americano", en Pedro Henríquez y otros estudios, Tempera, Buenos Aires, 1949, pág. 144, citado en Rodilla: Infortunios..., pág. 131.

18 Esplendores y miserias de los criollos, Cal y Arena, México, 1989, volumen 2, págs. 150151, citado en Rodilla: Infortunios..., págs. 131-132. 
go, Rodilla duda, como todos los estudiosos del tema, al considerar su veracidad: "Sea o no real el personaje Alonso Ramírez y sea o no verdadera la relación de su viaje, cuestiones estas muy debatidas por la crítica, lo que importa es el texto que ha llegado a nosotros y la lectura literaria que de él hagamos". ${ }^{19}$

Como vemos, con escasas excepciones, la crítica se ha mostrado escéptica al apreciar la historicidad del relato. En 1988 Lucrecio Pérez Blanco introduce su edición de los Infortunios dentro de la serie Crónicas de América, siguiendo lo que casi se había convertido ya en tópico de eruditos: el texto escrito por Sigüenza y Góngora vale más por su carácter literario que como fuente histórica. A pesar del predominio de este punto de vista entre los estudiosos, para historiadores como Francisco Vidargas, la obra entera del cosmógrafo, aún lo más obviamente literario, se ciñó siempre a las vistas "objetivistas" de Sigüenza y Góngora, cuyo metier de autor jamás se desvió, para Vidargas, de la meta de establecer la verdad objetiva por encima del encanto de la ficción. ${ }^{20}$ Concuerda con este dictamen el estudio lexicográfico meticuloso de Estelle Irizarry, posiblemente la prueba más convincente de que el léxico y el estilo de los Infortunios ofrecen claras pruebas de su autoría heterogénea y, por ende, prueba convincente de que el cosmógrafo actuó, como nos dice, de amanuense para el marinero.

En contra de estos razonamientos, el análisis literario escéptico ha dominado hasta tal punto la labor de los estudiosos que las voces discrepantes de los literatos e historiadores que se han planteado el tema de los infortunios de manera distinta apenas se han oído. Entre los que sí se han declarado por la historicidad del relato destacan Marcelino Menéndez y Pelayo, Cayetano Coll y Toste, Concha Meléndez, Josefina Rivera de Álvarez, y Manuel Álvarez Nazario. Para todos ellos el texto final lo produjo la combinación de hechos históricos con el pulimento estilístico del cosmógrafo de una manera u otra, con predominio del erudito sobre el marinero o viceversa, o por una colaboración equilibrada entre Alonso Ramírez y Sigüenza y Góngora. El resultado ineludible de tal tesis, que no desdeñó aceptar la existencia de Ramírez pese a la falta de pruebas fehacientes, es constituir a los Infortunios claramente en una fuente histórica de alta

19 Rodilla: Infortunios..., pág. 119.

20 "Don Carlos trabajó siempre con rigor las fuentes históricas, haciendo a un lado toda suposición que provocara errores. Esa actitud quedó manifiesta en el conocimiento histórico que, con objetividad, utilizó en sus obras", San Juan de Ulúa y Carlos de Sigüenza y Góngora, Instituto Veracruzano de Cultura, Veracruz, 1997, págs. 5-6. 
importancia para Puerto Rico y, secundariamente, para México. Otros, como Raúl Castagnino, se mantienen indecisos al preguntarse si Ramírez existió o no. Hacia el punto de vista opuesto se inclinan Willebaldo Bazarte Cerdán y David Lagmanovich, quienes opinan que la pluma de Sigüenza y Góngora pesó más que la lengua de Ramírez. Para J.S. Cummins y Alan Soons, quienes primero descubrieron algunas de las pruebas históricas para los Infortunios en 1984, el texto que produjo Sigüenza y Góngora se inspiró en las experiencias de un marinero que existió de verdad pero, como advirtió Estelle Irizarry al comentar sobre la edición de estos dos hispanistas, Cummins y Soons aceptaron con demasiada facilidad el carácter básicamente literario de los episodios tal y como los narró Sigüenza y Góngora. Las muchas correspondencias entre el texto de los Infortunios y las pruebas documentales que manejaron en 1984, limitadas a fuentes publicadas, no dieron el resultado esperado (aún así, Cummins y Soons separaron el derrotero del galeón de Manila desde Acapulco del resto del texto, añadiéndolo como apéndice al final de su edición para mostrar una parte del texto que lógicamente no debió de salir de la boca de un simple marinero puertorriqueño). ${ }^{21}$ Pese a estas pruebas históricas, muchas de las cuales existían ya en publicaciones fácilmente accesibles, en 1964 Enrique Anderson Imbert consideró que los Infortunios eran "una ficción" que le permitió a Sigüenza y Góngora describir magistralmente las aventuras de otra persona, pero sin llegar a ser "novela". Este cuento de viajes le sirvió de escenario al erudito mexicano para exhibir sus conocimientos geográficos y humanos. ${ }^{22}$

En 1996 Antonio Lorente Medina dedica un estudio minucioso a toda la obra de Sigüenza y Góngora dentro del cual se pronuncia irremisiblemente en favor de la interpretación histórica de los Infortunios e imbrica al libro con los otros textos históricos del autor dentro de un género que Lorente Medina demuestra convincentemente ser típico del autor del XVII, enumerando obras parecidas como Piedad heroica de don Fernando Cortés (fragmento, 1663), Noticia cronológica de los reyes, emperadores, gobernadores, presidentes y virreyes de...México (1682?), Paraíso occidental (1684), Relación de lo sucedido a la Armada de Barlovento (1691), Triunfo de la justicia española en el castigo de la alevosía francesa (1691) y el

21 Infortunios que Alonso Ramírez, natural de San Juan de Puerto Rico, padeció, Tamesis Texts, London, 1984, págs. 75-76; Irizarry: Infortunios de Alonso Ramírez..., págs. 11-13.

22 Anderson Imbert, Enrique: Historia de la literatura hispanoamericana, Fondo de Cultura Económica, México, 1964, pág. 95. 
Mercurio Volante (1695). ${ }^{23}$ La reseña de los estudios sobre la historicidad y ficcionalidad de los Infortunios que incluye Lorente Medina en su análisis de la formación de la conciencia criolla mexicana es, sin lugar a dudas, la mejor y más completa que se haya producido, hecho que resalta la importancia de su tesis de que "es chocante" que para probar la ficcionalidad del texto "ha habido estudiosos que han utilizado" precisamente las dos ediciones que salieron en 1984 - la de Cummins y Soons publicada en Londres más la de William G. Bryant en Caracas, con prólogo nada menos que de Irving Leonard $-{ }^{24}$ que conjuntamente forman las voces discrepantes en el "mare magnum de opiniones que abogan por el carácter novelesco de Infortunios". Aunque Cummins, Soons y Bryant demostraron que existían pruebas no sólo para comprobar la existencia de la mayoría de los personajes que menciona Alonso Ramírez sino también para el contexto en general de lo que afirmó haber sufrido con los piratas ingleses en aguas asiáticas, la crítica literaria ha dejado de lado lo que consta desde la publicación del trabajo de los tres grandes hispanistas en 1984: "No obstante esta evidencia, los estudiosos aparecidos posteriormente han ignorado las aportaciones esenciales de estos críticos". ${ }^{25}$

\section{La defensa aristocrática del imperio en 1690 y la historicidad de los Infortunios}

Conocidísimo es el tema de la decadencia de España en el siglo XVII, aunque los estudios sobre el reino de Carlos II basados en fuentes archivísticas que van saliendo últimamente contribuyen en gran parte a derrocar la visión homogeneizadora de la tesis "decadentista". Las investigaciones de Antonio Ramón Peña Izquierdo, por ejemplo, ponen de relieve la vitalidad de la política aristocrática de la familia Portocarrero y Palma como contrapartida a la narración de bancarrotas, corruptelas, y desastres militares bajo el último de los Austrias. ${ }^{26}$ Lo menciono específicamente pues el análisis de Peña Izquierdo resulta significativo para establecer el contexto histórico

23 Reconoce el autor que trazaron la misma hipótesis, entre otros, Leonard Irving y William Bryant.

24 Seis obras. Infortunios...

25 La prosa de Sigüenza..., pág. 171.

26 La crisis sucesoria de la monarquía española, tesis doctoral dirigida bajo Lluís Roura Aulinas, Universidad Autónoma de Barcelona, 2005. 
auténtico de los Infortunios. La importancia de la prueba documental que he descubierto para la historicidad de Alonso Ramírez radica en parte en el entramado político de las intrigas cortesanas de los Portocarrero y Palma con la otra gran familia del Madrid de los años noventa, los Infantado.

En principio vale recordar que cuando Alonso Ramírez llega en la primavera de 1690 a la ciudad de México, al final de sus aventuras, el virrey de Nueva España era don Gaspar de la Cerda Silva y Mendoza, conde de Galve, hermano menor de don Gregorio, el mismo duque del Infantado cuyo retrato todavía cuelga en la sala de Velázquez del Museo del Prado. Los Infantado y Galve estaban en esas fechas al frente de un partido aristocrático organizado desde Europa pero que abarcaba a las Américas y a Asia. Se oponían a las reformas propuestas por los Portocarrero y sus seguidores, que propugnaban una visión gubernamental sinodial en contra del predominio de validos en la corte de la reina madre Mariana de Austria, cuyo poder sobre el pobre Carlos II sobrevivió a las crisis de los años setenta. ${ }^{27}$ Los Portocarrero se encontraban rezagados por sus rivales, los Infantado-Galve, quienes se convirtieron en los favoritos de Mariana de Austria, regente hasta los años setenta, y de Mariana de Neoburgo, la nueva reina después de la muerte de la primera esposa de Carlos II, tras el desastre del golpe de estado de don Juan José en 1678-1679. Aunque se ha pensado que Mariana se retiró de la política tras 1677-1679, María Dolores Álamo Martell recuerda que el gran biógrafo alemán de Carlos II, Ludwig Pfandl, hace años sospechó fundadamente que la reina madre siguió rigiendo las fortunas de España después de la muerte de don Juan José. En 1685 "la destrucción del primer ministro", el duque de Medinaceli, sucesor del príncipe bastardo, se debió, según Alamo Martell y Pfandl, a "las conspiraciones dirigidas, en gran medida, por la reina madre". Pese a la imagen de progenitora desterrada, Mariana todavía contaba con aliados en la corte de su hijo Carlos II, particularmente los Infantado. El final de Medinaceli lo causó él mismo por su "torpeza política al haber infravalorado a la reina viuda". ${ }^{28}$ La gobernación de Oropesa entre 1685 y 1691 igualmente no

27 Véanse como muestras de la reivindicación de la importancia de doña Mariana los trabajos de López-Cordón Cortezo, María Victoria: "Entre damas anda el juego: las camareras mayores de Palacio en la Edad Moderna", Cuadernos de Historia Moderna, Anexo II, 2003, págs. 128-148 y Goodman, Eleanor: "Conspicuous in her Absence: Mariana of Austria, Juan José of Austria, and the Representation of Power", en Theresa Earenfight, Queenship and Political Power in Medieval and Early Modern Spain, Ashgate, Aldershot, Inglaterra y Burlington, Vermont, 2005.

28 "El VIII Duque de Medinaceli: Primer Ministro de Carlos II", en Escudero, José Antonio: Los validos, Universidad Rey Juan Carlos, Dykinson, Madrid, 2004, pág. 566. 
debió de plasmarse sin la anuencia de la reina madre. Con don Gaspar de virrey en Nueva España y don Gregorio de amigo del rey y su madre en Madrid, se establece el contexto para el poder del partido anti-Portocarrero. Sin pararnos a considerar las complicadísimas políticas de tal alianza entre Corona y aristocracia, debemos hacer hincapié, no obstante la inseguridad documental para semejantes generalizaciones, en la importancia de reconocer que en las manos de don Gregorio y don Gaspar se reunían, según los estudios de Henry Kamen, la mayor riqueza de los grandes de España, los estados correspondientes al ducado del Infantado, más el puesto de mayor prestigio y lustre entre las posesiones coloniales, el virreinato de Nueva España, coyuntura que forma el telón de fondo para el documento que vamos a leer. ${ }^{29}$

En 1690 el virrey conde de Galve, después de dos años de gobierno, se sentía frustrado por los problemas que le causaba la falta de dinero, a semejanza de la queja del rey Felipe IV en 1657. Las peticiones que le mandaban los consejeros desde Madrid para que enviara más galeones y con más plata, urgentemente necesarios para los gastos europeos, le parecían al virrey imposibles de cumplir, puesto que la defensa de Nueva España contra las depredaciones de piratas y bucaneros y las ambiciones de Luis XIV en Luisiana exigían cada año mayores recursos. Durante el mandato de Galve, se volvió a poner en pie de guerra a la Armada de Barlovento, se amurallaron ciudades en el Caribe, se extendieron las fortificaciones de las principales plazas de Nueva España y se organizó la reconquista de la provincia de Nuevo México. ${ }^{30}$ En el verano de 1690 la pesadilla de la devastación del puerto de Veracruz en 1683 por un verdadero ejército de bucaneros seguía vigente en la corte virreinal, así como la

29 Spain in the Later Seventeenth Century, 1665-1700, Longman, Londres y Nueva York, 1980, pág. 232; sin embargo al parecer del duque de Maura siguen siendo los Medinaceli, entre todos los grandes de Carlos II, los más poderosos y ricos, Vida y reinado de Carlos II, Espasa-Calpe, Madrid, 1942, vol. 1, pág. 197.

30 Se pueden sacar a colación las famosas obras del ingeniero Jaime Franck en San Juan de Ulúa, cuyas "antiguas obras" fueron "corregidas y perfeccionadas" por él entre 1689 y 1692, así como su trabajo sobre los "ocho baluartes terraplenados" en Campeche, la finalización de "las obras básicas del fuerte de San Marcos" en San Agustín de la Florida allá por el año 1695, la construcción larga y penosa del recinto amurallado de La Habana empezada en 1674 y sin acabar hasta 1702, la reconstrucción del castillo del Morro de Santiago de Cuba después del terremoto de 1678, que también ocasionó costos por los serios daños que efectuó en varias fortificaciones importantes de Puerto Rico, cuya remodelación continuó a buen paso durante los años de Galve, y el restablecimiento de "la precaria fortificación" del castillo de San Felipe del Golfo Dulce en Guatemala tras el asalto de piratas en 1680, Gutiérrez, Ramón: Fortificaciones en Iberoamérica, Ediciones el Viso, Fundación Iberdrola, Madrid, 2005, págs. 82, 92, 109, 118, 141, 151-167,169. 
perturbación causada en la política de Galve por las noticias de la expedición francesa al valle del Misissipi liderada por La Salle, claramente un fracaso dadas las noticias que recibió entre 1686 y 1690, pero decididamente aviso aciago de problemas que le llevarían a darle a Madrid argumentos en favor de la fundación de una nueva colonia en la Florida (Pensacola). ${ }^{31}$ En junio de 1690 no había llegado todavía la confirmación por vía del gobernador de Coahuila de que la expedición de La Salle había fracasado, ${ }^{32}$ y Galve preparaba contraataques, confiando en las buenas noticias de que el nuevo rey de Inglaterra, Guillermo III de Orange, acababa de deshacer la gran diplomacia europea de Luis XIV al decidirse, tras bastante esfuerzo por parte de Ronquillo, embajador español en Londres, a unirse con España y Holanda para contrarrestar el poder galo. En la coyuntura, pues, de la primavera de 1690 se reunían óptimas condiciones para los planes coloniales, imperiales y europeos de don Gaspar y su hermano el duque del Infantado.

No es de extrañar, por consiguiente, que la aparición de Alonso Ramírez, víctima de piratas y heroico sobreviviente español (es decir hispano-puertorriqueño), le sugiriera al virrey la composición de un libro que pudiera distribuir a la camarilla política de los Infantado en Madrid como propaganda que destacaba la importancia de sus planes para la defensa de Nueva España. Es precisamente lo que hizo, según un documento del Archivo de la Casa Ducal de Osuna, el cual evidencia que no es verdad que Alonso Ramírez no existió, como pensaron muchos críticos literarios, ni mintió Sigüenza y Góngora al narrar su versión de cómo se formuló el texto de los "trabajos" que padeció el marinero puertorriqueño, según consta en la carta siguiente, escrita de puño y letra por don Gaspar el primero de julio de 1690 a su hermano en España:

Excelentísimo señor, hermano, amigo y señor mío: Acompañan a esta veinte relaciones del viaje que hizo Alonso Ramírez, natural de Puerto Rico, desde las islas Filipinas hasta la provincia de Campeche donde se perdió, que habiéndole mandado viniese a esta corte hice le tomasen declaración de la derrota e infortunios que padeció en tan inaudita navegación hasta estos tiempos, que por ser bien rara y peregrina la remito a Vuestra Excelencia. He hecho se imprima para poder enviar muchos duplicados a V.E. por si gustase repartir entre los amigos, que yo sólo la envío al Marqués

31 Véase Dunn, William Edward: Spanish and French Rivalry in the Gulf Region of the United States, 1678-1702, University of Texas Press, Freeport y Nueva York, 1971 y Leonard, Irving: The Spanish Approach to Pensacola, 1689-1693, Quivira Society, Albuquerque, Nuevo México, 1939.

32 AGI, México, 617 (61-6-21), citado por Leonard: The Spanish Approach..., pág. 119. 
de los Vélez, de que doy cuenta a V.E., cuya excelentísima persona guarde Dios muchos años como he menester. México, 1 de julio de 1690. A los pies de V.E. su servidor y mayor amigo, El Conde de Galve [Firma y rúbrica holográfica]..$^{33}$

Sin lugar a dudas, este documento prueba de una vez por todas la historicidad fundamental de los Infortunios, es decir, el carácter eminentemente histórico de la creación del texto del libro, lo cual, empero, no constituye lo mismo que decir que debemos aceptar como verídicos todos los detalles que contiene. Cabe afirmar que si esta carta demuestra que no mintieron don Carlos y Alonso al contarnos cómo se formuló el texto, nos sugiere muchísimas preguntas sobre los actos que posiblemente dieron lugar a la formación de la curiosa narración de las desventuras del puertorriqueño. Más allá de la cuestión general sobre la historicidad de los Infortunios, que ya, según hemos visto, varios estudiosos sospechaban era en sí ficticia dadas las pruebas internas, textuales, y publicadas para su contexto histórico, debemos resaltar que la misiva del virrey Galve a su hermano demuestra que los Infantado-Galve se interesaron por la historia de Alonso Ramírez no sólo porque contenía una "inaudita navegación...bien rara y peregrina" sino también porque les ofreció material propagandístico para influir en las decisiones que tomarían el marqués de los Vélez y sus "amigos" en los consejos gubernativos en la corte.

Poco después se empezaron a registrar los resultados desafortunados de la política personal de Galve e Infantado, el primero víctima de ambiciones virreinales que superaban los recursos financieros coloniales a la vez que su proceder y sus indiscreciones le comprometían de cara a las exigencias de la mayoría de los consejeros en la metrópoli; el segundo, don Gregorio, murió a finales de 1693, dejando al hermano en las Américas sin el respaldo diplomático que venía ofreciéndole dentro de la corte madrileña. Además, con vistas a la reforma iniciada en 1691 por Oropesa y el marqués de los Vélez, antiguo "amigo" de los Infantado, que impulsaba mecanismos para contrarrestar "el fraude e impagos", ${ }^{34}$ la actuación de Galve como virrey le expuso, especialmente a partir del verano de 1692, a las críticas de detractores que tildaron su gobierno de absolutismo militar, tema que se soslayó con dificultad en la residencia concluida tras la muerte de Galve en 1697 por don Baltasar de Tomás, el juez más antiguo de la

33 Archivo Histórico Nacional, Sección Nobleza, Osuna, 55, 61.

34 Cárceles de Gea, Beatriz: Reforma y fraude fiscal en el reinado de Carlos II: La Sala de Millones (1658-1700), Banco de España, Madrid, 1995, pág. 76. 
Audiencia de México. ${ }^{35}$ Un grupo envió cartas anónimas al citado juez, por ejemplo, para delatar a Galve en 1692, haciéndole responsable, entre otras cosas, de los desastres agrícolas y económicos que desembocaron en el motín que a principios de julio asoló varias salas del palacio, el archivo municipal y otros edificios en el centro de la ciudad de México. ${ }^{36}$ La situación empeoró. Dos años después del motín, a finales de diciembre de 1694, y en nombre del rey, los consejeros criticaron duramente a Galve, increpándole por haber atropellado los derechos administrativos de la Audiencia y los oficiales reales en Nueva España. ${ }^{37} \mathrm{Al}$ morir don Gaspar el 12 de marzo de 1697 cerca del Puerto de Santa María en la casa de su amigo, el duque de Alburquerque, al final de su tornaviaje a España, ya se había desmoronado el plan ambicioso de los Galve-Infantado para ensalzar el poder imperial de la corona austríaca. Aunque en enero de 1695 se frustró el golpe de estado de su más acérrimo contrario, Luis Manuel Fernández Portocarrero, cardenal y arzobispo de Toledo (1635-1709), salió éste ganador a la larga con el establecimiento de los Borbones a partir de 1700.

Esta contribución al estudio del famoso texto de Sigüenza y Góngora no pretende ser exhaustiva en cuanto al tema de la historicidad de los detalles contenidos en el relato de Alonso Ramírez; como ya hemos anotado, queda esto pendiente hasta la aparición de mi estudio monográfico sobre el tema. Sin embargo, el presente trabajo contribuye a deshacer mentiras: a pesar de que hace años varios estudiosos coincidieron con Antonio Lorente Medina "en subrayar la existencia real del protagonista de Infortunios", ahora por primera vez, utilizando la carta de don Gaspar, podemos comprobar de manera fidedigna su existencia, su relato, y el papel que de modo seguro desempeñó Sigüenza y Góngora en la redacción del texto (aunque no le mencionara explícitamente el virrey en su misiva). Es posible, como dijo Lorente Medina hace ya más de diez años, que "se encuentre Alonso Ramírez entre los 'catorce oficiales' que acompañaban a Juan Enríquez

35 Se le imputaron a Galve muchos cargos pero en sus determinaciones finales el Consejo de Indias le absolvió. Existen, no obstante, pruebas de que esta autoridad se inmiscuyó en las corruptelas típicas de los gobernadores de finales del siglo diecisiete, en el examen de las cuales me detengo en el estudio monográfico, The Spanish Empire Strikes Back.

36 AGI, Patronato, 226, para cuya consulta véase el estudio preliminar de Irving Leonard en su edición de Carlos de Sigüenza y Góngora, Alboroto y motín de México del 8 de junio de 1692, Museo Nacional de Arqueología, Historia y Etnografía, México, 1932, y, en general, Feijóo, Rosa: "El tumulto de 1692", Historia Mexicana, 14, IV-VI, 1965, págs. 656-679.

37 AGI, Escribanía 230 B, carta del rey al Conde de Galve, Madrid, 30 de diciembre de 1694, ff. 586-587. 
Barroto durante la campaña del Guarico en el patache Santo Cristo de San Román" en 1690-1691. ${ }^{38}$ Es aún más probable que la autojustificación de Ramírez motivara la primera formulación del texto de los Infortunios, si tenemos en cuenta las dificultades que experimentaron los contemporáneos de Ramírez que, como él, viajaron con piratas para quitarse de encima la sospecha de colaboración con ellos (piénsese en las vidas de Exquemeling, Ravenau de Lussan, Dampier, y Kidd), cargo que claramente el regidor y fiel ejecutor en el Yucatán, don Ceferino de Castro y Velasco, atribuyó a Alonso en 1690 según consta al final de su relato. Por consiguiente la trama más intrincada del momento histórico de 1690, el contexto en que se ideó el relato de los Infortunios, obedeció no sólo a la lógica de los proyectos imperiales y personales de Galve e Infantado, y de Sigüenza y Góngora, sino también - y primordialmente- a los deseos de Alonso Ramírez de probar que tenía derecho legal al cargamento valioso del buque que naufragó a causa de la ruta peligrosísima que él mismo le trazó por mares caribeños hasta México a finales de 1689.

El patronazgo del virrey le sirvió a Alonso de cobertura gubernamental contra las sospechas de los oficiales reales yucatecos de que había colaborado con los piratas ingleses en sus depredaciones, a mi manera de ver, indicios comprobados por un análisis detenido de todo el contexto histórico de las peripecias de Alonso entre 1687 y 1690. Alegaron estos oficiales, basándose en la Bula de la Santa Cruzada, que el buque y su contenido, como presa tomada de piratas, por derecho canónico pertenecían a la Santa Cruzada, un recurso legal nada "frívolo", pese a lo que dijo Alonso al final de los Infortunios. Fueron Galve y don Carlos los resortes de Alonso para remediar el desastre del naufragio que le expuso a perder el valioso cargamento. Con el motivo de contrarrestar las delaciones en Mérida aprovechó Alonso la oportunidad del interés que suscitó su historia para apelar su causa al virrey. Irremisiblemente, dadas las circunstancias del naufragio, mintió el histórico Alonso al enfrentarse a la posibilidad de perderlo todo como sospechoso de piraterías, pero no mintió el conde de Galve en julio de 1690 al decirle a su hermano por escrito que acababa de conocer a "Alonso Ramírez, natural de Puerto Rico", el cual, le explicó al duque su hermano, había viajado "desde las islas Filipinas hasta la provincia de Campeche donde se perdió"; ni tampoco mintió Sigüenza y Góngora al repetir en su

38 Archivo General de la Nación, México, Reales Cédulas, vol. XXIV, expediente 92, ff. 274 304, Lorente Medina, Antonio: La prosa de..., 175n.111. 
texto lo que el virrey le explicó al duque del Infantado, que "habiéndole mandado" a Alonso Ramírez que "viniese a esta corte hice le tomasen declaración de la derrota e infortunios que padeció". La descripción manuscrita de la "derrota" y los "infortunios" que tomó el secretario del virrey entre mayo y junio de 1690, claro está, se plasmaron en el famoso libro del cosmógrafo, cuyo manuscrito también se ha perdido. Acaso algún día descubriremos estas fuentes principales en algún legajo perdido allá por los archivos de la monarquía española bajo Carlos II.

Recibido el 11 de junio de 2007 Aceptado el 23 de julio 2007 